\title{
Microstructure and Glass Phase of Inorganic Binder Coated on Mold for Thin Casting
}

\author{
Eun-Hee Kim, ${ }^{1}$ Geun-Ho Cho, ${ }^{1}$ Yeon-Gil Jung, ${ }^{1}$ Je-Hyun Lee, ${ }^{1}$ \\ Baig-Gyu Choi, ${ }^{2}$ and Chang Young Jo ${ }^{2}$
${ }^{1}$ School of Nano and Advanced Materials Engineering, Changwon National University, No. 9 Sarim-dong, Changwon, Gyeongnam 641-773, Republic of Korea
${ }^{2}$ High Temperature Materials Research Group, Korea Institute of Materials Science, 797 Changwondaero, Changwon, Gyeongnam 641-831, Republic of Korea

Correspondence should be addressed to Eun-Hee Kim, udam99@changwon.ac.kr and Yeon-Gil Jung, jungyg@changwon.ac.kr

Received 11 June 2012; Accepted 4 December 2012

Academic Editor: Zhengren Huang

Copyright (C) 2012 Eun-Hee Kim et al. This is an open access article distributed under the Creative Commons Attribution License, which permits unrestricted use, distribution, and reproduction in any medium, provided the original work is properly cited.

\begin{abstract}
A new dual dipping process has been introduced for the increase in the fracture strength of casting mold through the effective glassification of inorganic binder precursors. Two different dipping processes have been employed to investigate the reactivity of the precursors. Process $\mathrm{I}$ is that the substrate was coated with a sodium oxide $\left(\mathrm{Na}_{2} \mathrm{O}\right)$ precursor through dipping in the solution, and then a silicon dioxide $\left(\mathrm{SiO}_{2}\right)$ precursor was coated onto the substrate coated with the $\mathrm{Na}_{2} \mathrm{O}$ precursor. Process II is the inverse coating sequence for process I. In the case of the mold prepared by process I, the glass phase converted from the precursors is uniformly observed at the surface of the particle and the interface between particles, compared with that by process II, inducing that the fracture strength of the mold prepared by process I is significantly improved. In addition, when the PDMS without a sol-gel reaction was used as the $\mathrm{SiO}_{2}$ precursor, especially in process II, the glass phase is not absolutely observed at the surface of the particle owing to the evaporation of PDMS and Na ion during the heat treatment, resulting in the collapse of the mold sample after the heat treatment.
\end{abstract}

\section{Introduction}

Recently, the convert mold process has been introduced to fabricate molds in a thin casting $[1,2]$. The convert mold process has many advantages, such as high strength, excellent collapse, easy processability, and high thermal stability, making it useful in fabricating components of automobile and aircraft. Typically, the convert mold process is divided into five main processes: (1) fabricating the starting mold coated with an organic binder, (2) dipping the coated mold into a slurry containing inorganic binder precursors, (3) 1st drying for $1 \mathrm{~h}$ at $80^{\circ} \mathrm{C}$, (4) 2nd drying for $1 \mathrm{~h}$ at $200^{\circ} \mathrm{C}$, and (5) heat treatment for $1 \mathrm{~h}$ at $1000^{\circ} \mathrm{C}$, resulting in the conversion of the organic binder-coated mold to the inorganic binder-coated mold $[3,4]$. The hydrolysis and condensation reactions (generally called a sol-gel reaction) and glassification take place during the above (3 and 4) and (5) processes, respectively [5-7]. The mechanical and thermal properties of the mold are induced from the glass phase generated during the heat treatment process, even though the organic binder is decomposed after the heat treatment. Therefore, the generated glass phase must be homogeneously formed on the surfaces of starting particles in the mold as well the conversion efficiency of inorganic binder precursors into the glass phase should be increased, which are related to the reactivity between precursors. Our early work has researched about the new inorganic precursors without the sol-gel reaction instead of the inorganic binder used in the conventional convert mold process, showing a higher glassification efficiency of inorganic binder precursors and a better fracture strength. In addition, the morphology and structure of inorganic binder obtained after the dry and heat treatment processes were investigated in detail $[8,9]$. However, the previous works were related to the new precursors for the increase in the strength of the mold. 


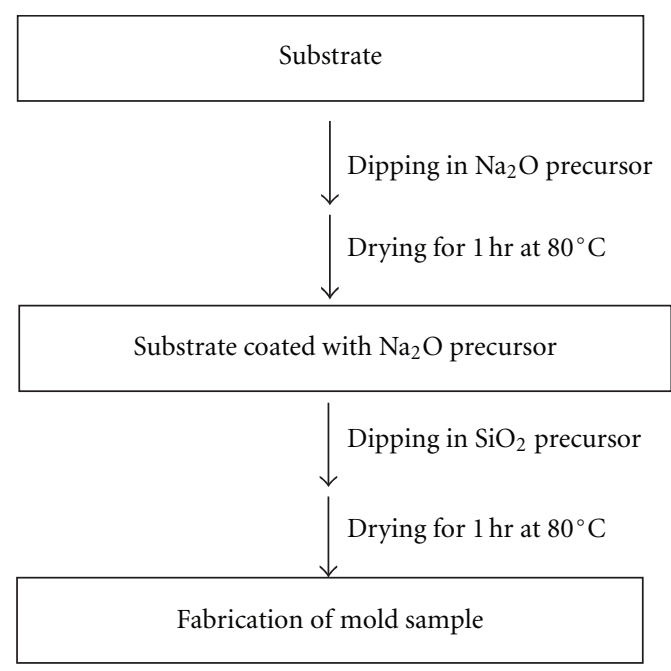

(a)

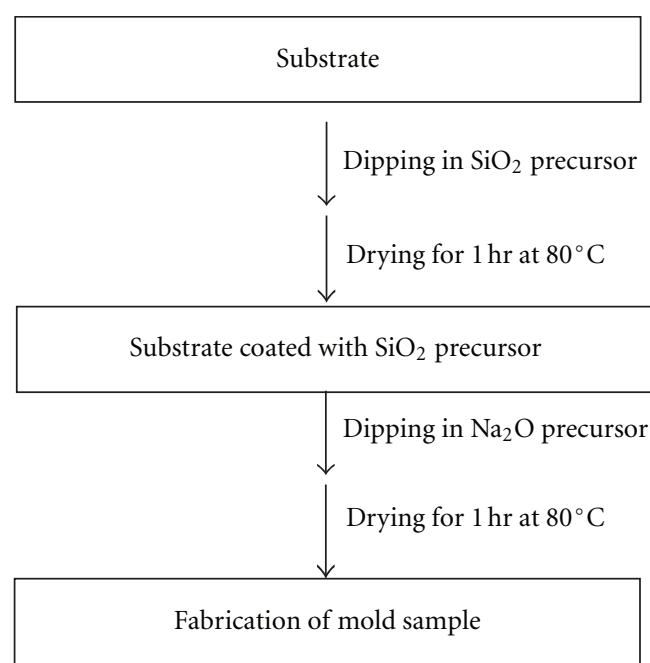

(b)

FIGURE 1: Schematic diagram for fabricating mold samples through the new dual dipping process: (a) process I and (b) process II.

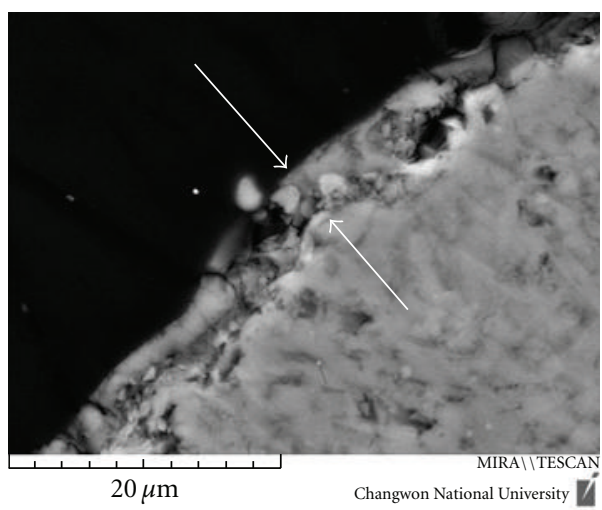

(a)

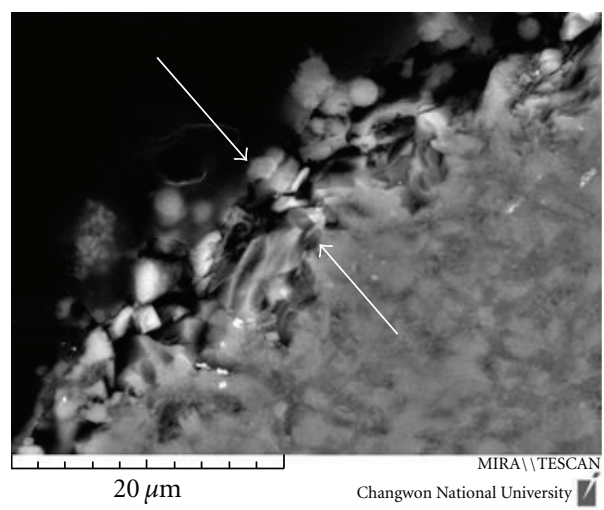

(b)

FIGURE 2: SEM morphologies of particle surfaces in mold samples prepared by (a) process I and (b) process II before the heat treatment. TEOS was used as the $\mathrm{SiO}_{2}$ precursor. Arrows indicate the coated layers in each particle.

For that reason, in this work, a new dipping process has been introduced for inducing the uniform coating of glass phase and improving the conversion efficiency of inorganic binder precursors into the glass phase, leading to the optimum fracture strength of the mold for the thin casting. The inorganic binder system consisted of a mixture of alkyl silicate (or siloxane compound) and sodium alkoxide used as the silicon dioxide $\left(\mathrm{SiO}_{2}\right)$ and sodium oxide $\left(\mathrm{Na}_{2} \mathrm{O}\right)$ precursors, respectively. Respective precursors were independently coated on the particles of the mold through the continuous dipping process, called a dual dipping process, compared with the convention process dipped into a mixture with two precursors at a time. The properties of mold samples prepared by the dual dipping process were measured using various analytical techniques. The influences of precursor species and dipping sequence in the dual dipping process on fracture strength have been investigated and discussed based on the microstructures observed before and after the heat treatment.

\section{Experimental Procedure}

Composite binder systems for fabricating mold samples through the dual dipping process were prepared using tetraethyl orthosilicate (TEOS, Sigma-Aldrich Korea, Yongin, Korea) of silicate type or poly(dimethyl siloxane) (PDMS, bp $160^{\circ} \mathrm{C}$, Sigma-Aldrich Korea, Yongin, Korea) of siloxane type used as an $\mathrm{SiO}_{2}$ precursor, and sodium methoxide (NaOMe, Sigma-Aldrich Korea, Yongin, Korea) used as an $\mathrm{Na}_{2} \mathrm{O}$ precursor. The size of a substrate prepared with the bead composed of $\mathrm{SiO}_{2}$ and $\mathrm{Al}_{2} \mathrm{O}_{3}$ was $10 \times 10 \times$ $50 \mathrm{~mm}$, which was coated with an organic binder of phenol resin. In this work, two different dual dipping processes were employed for preparing mold samples, as shown in Figure 1. In the first process, the substrate was coated with the $\mathrm{Na}_{2} \mathrm{O}$ precursor, and then the treated substrate was coated with the $\mathrm{SiO}_{2}$ precursor, which is process $\mathrm{I}$. In the second process, the coating sequence of process I was inversed, which is process II. The mold samples coated with the precursors were dried 

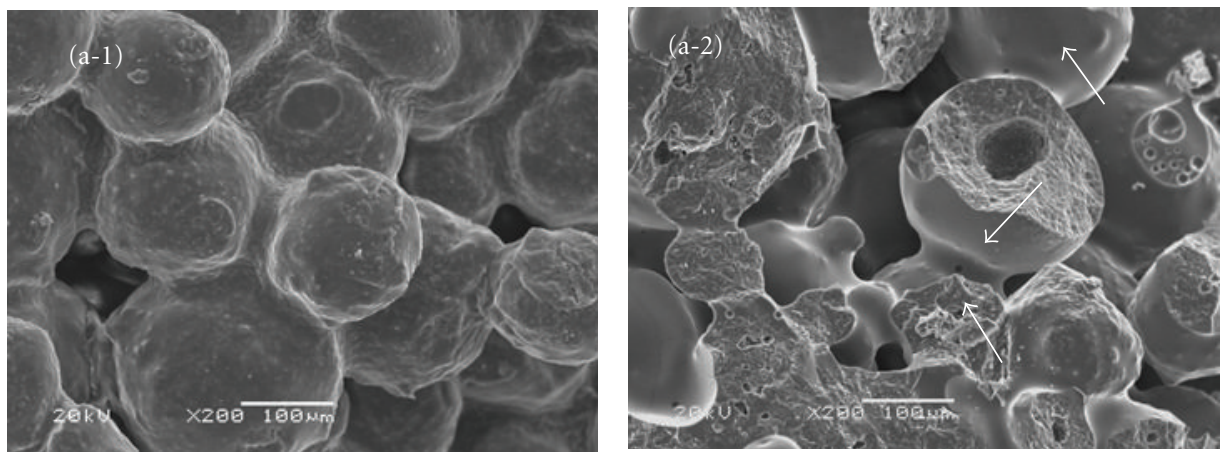

(a)
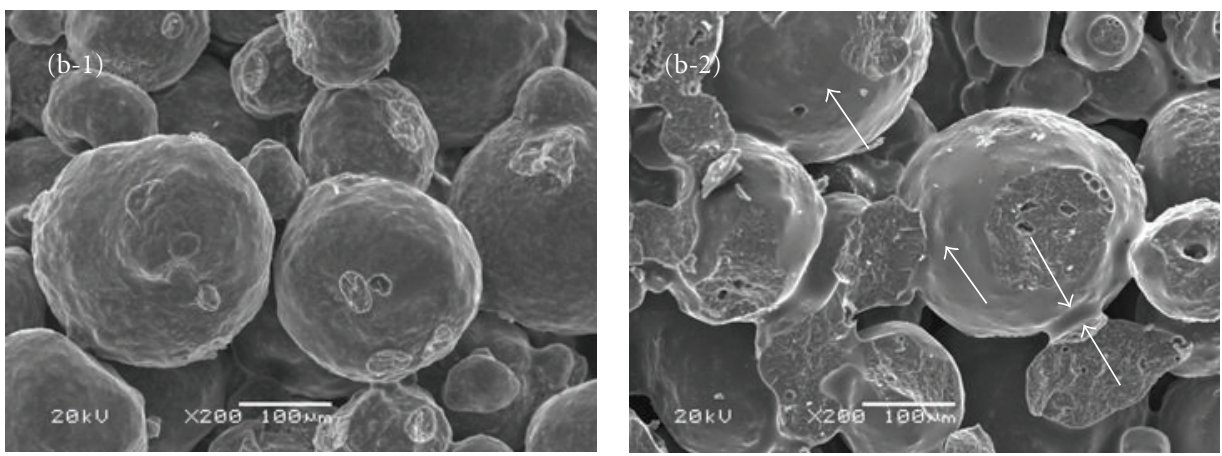

(b)

FIgURE 3: SEM morphologies on the fracture surfaces of mold samples through process I as a function of $\mathrm{SiO}_{2}$ precursor: (a) TEOS and (b) PDMS. Each number indicates SEM morphologies before and after the heat treatment, respectively. Arrows indicate the glass phase formed in mold samples.

TABLE 1: Basic formulations and experimental ranges to prepare mold samples through the new dual dipping process.

\begin{tabular}{lcccc}
\hline $\begin{array}{l}\text { Run } \\
\text { number }\end{array}$ & $\begin{array}{c}\mathrm{SiO}_{2} \\
\text { precursor }\end{array}$ & $\begin{array}{c}\mathrm{Na}_{2} \mathrm{O} \\
\text { precursor }\end{array}$ & Process & $\begin{array}{c}\text { Condition of } \\
\text { heat treatment }\end{array}$ \\
\hline Run-1 & TEOS & & Process I & \\
Run-2 & PDMS & NaOMe & & $1000^{\circ} \mathrm{C}$ for $1 \mathrm{~h}$ \\
Run-3 & TEOS & & Process II & \\
Run-4 & PDMS & & & \\
\hline
\end{tabular}

at $80^{\circ} \mathrm{C}$ for $1 \mathrm{~h}$ after each coating or dipping process, and then heat-treated at $1000^{\circ} \mathrm{C}$ for $1 \mathrm{~h}$. The molten metal based on iron $(\mathrm{Fe})$ was poured into the real mold prepared through process I with TEOS as the $\mathrm{SiO}_{2}$ precursor for thin casting. Basic formulations and experimental ranges for preparing the mold through the dual dipping process are shown in Table 1.

The surface morphology and microstructure before and after the heat treatment were observed using a scanning electron microscope (SEM, JEOL Model JSM-5610, Tokyo, Japan). The fracture strength of mold samples after the heat treatment was measured using a universal testing machine (UTM, Instron 5566, Instron Corp., Norwood, MA, USA) in the bending mode at a rate of $0.5 \mathrm{~mm} \mathrm{~min}^{-1}$. Tests were carried out at room temperature, and five runs were performed to determine the standard deviation of the strength. The support spans of the low and upper noses were $2.5 \mathrm{~cm}$ and $1.0 \mathrm{~cm}$, respectively.

\section{Results and Discussion}

The reaction mechanism of precursor materials is divided into hydrolysis reaction, sol-gel reaction, and heat-treatment stages $[3,4]$, as shown in the following reactions.

Hydrolysis reaction:

$$
\mathrm{NaOR}+\mathrm{H}_{2} \mathrm{O} \longrightarrow \mathrm{ROH}+\mathrm{NaOH}
$$

Sol-gel reaction:

$$
\begin{gathered}
(\mathrm{RO})_{3} \mathrm{Si}\left[\mathrm{O}-\mathrm{Si}(\mathrm{OR})_{2}\right]_{n} \mathrm{OR}+(n+2) \mathrm{H}_{2} \mathrm{O} \\
\longrightarrow(n+1) \mathrm{SiO}_{2}+2(n+2) \mathrm{ROH}
\end{gathered}
$$

where $\mathrm{NaOR}, \mathrm{ROH}, \mathrm{NaOH},(\mathrm{RO})_{3} \mathrm{Si}\left[\mathrm{O}-\mathrm{Si}(\mathrm{OR})_{2}\right]_{n} \mathrm{OR}$, and $\mathrm{SiO}_{2}$ denote sodium alkoxide, an alcohol, sodium hydroxide, alkyl silicate, and silicon dioxide (silica), respectively $[5,10]$. $\mathrm{NaOR}$ is hydrolyzed to form $\mathrm{NaOH}$ (by (1)), and alkyl silicate is hydrolyzed to form silica and alcohol (by (2)).

Heat-treatment reaction:

$$
2 \mathrm{NaOH}+\mathrm{SiO}_{2} \longrightarrow \mathrm{Na}_{2} \mathrm{O} \cdot \mathrm{SiO}_{2}+\mathrm{H}_{2} \mathrm{O}
$$



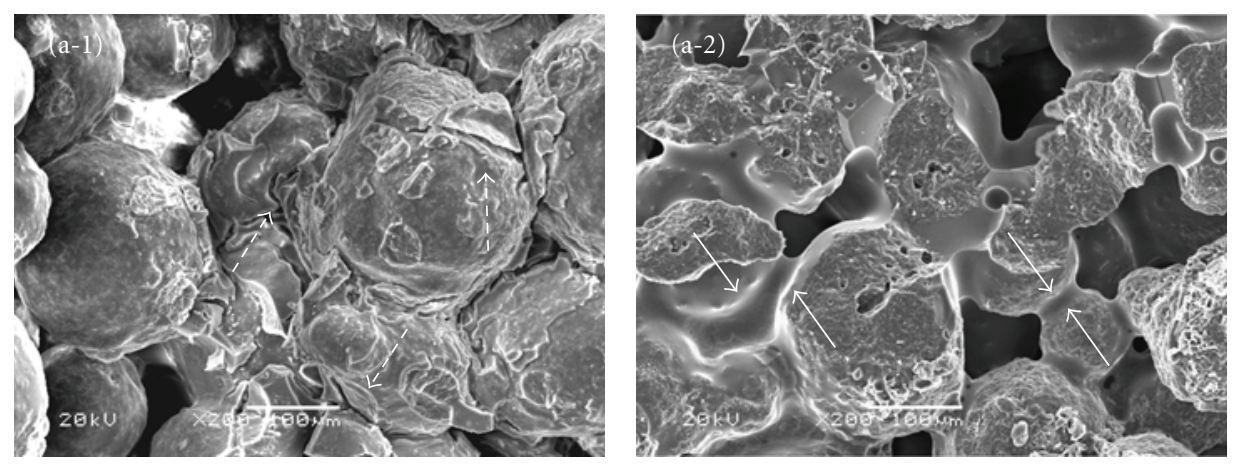

(a)
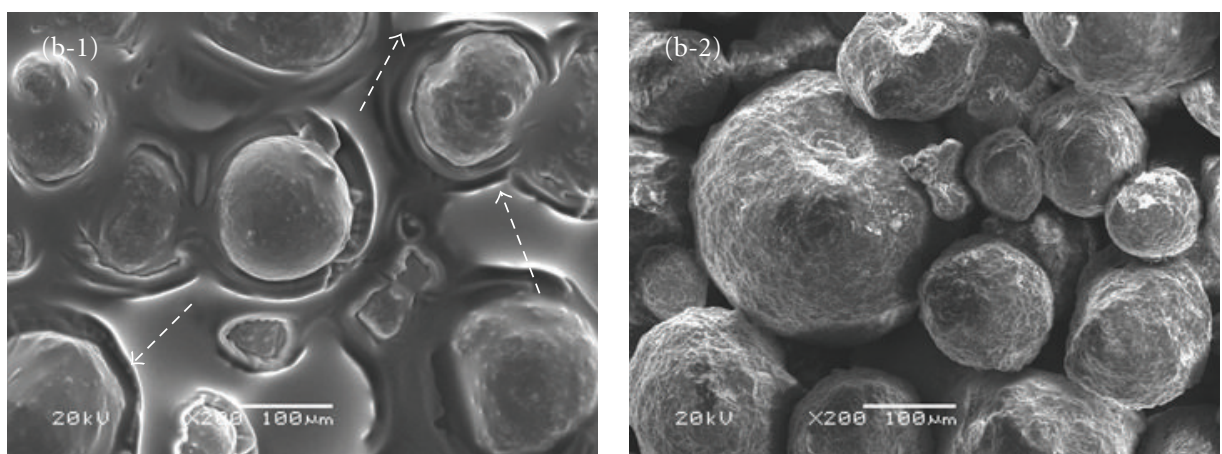

(b)

FIGURE 4: SEM morphologies on the fracture surfaces of mold samples through process II as a function of $\mathrm{SiO}_{2}$ precursor: (a) TEOS and (b) PDMS. Each number indicates SEM morphologies before and after the heat treatment, respectively. Dotted and solid arrows indicate the crack created (series-1) and glass phase formed (series-2) in mold samples, respectively.

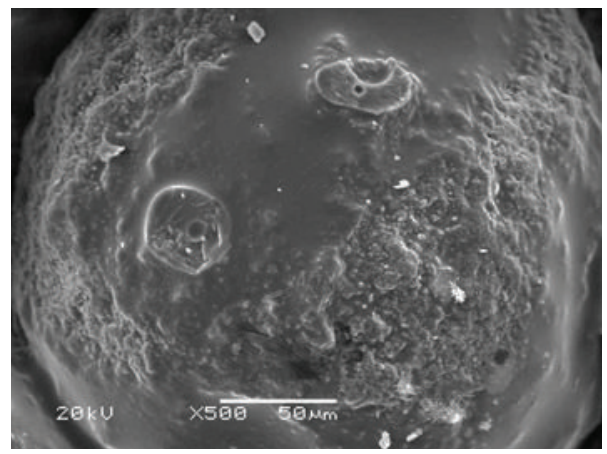

(a)

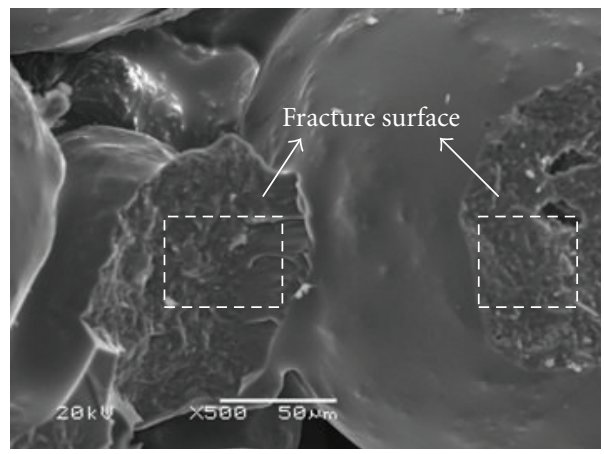

(b)

FIGURE 5: SEM morphologies of particle surfaces in mold samples prepared by (a) conventional process and (b) process I with TEOS as the $\mathrm{SiO}_{2}$ precursor after the heat treatment.

The glass phase of sodium silicate $\left(\mathrm{Na}_{2} \mathrm{O} \cdot \mathrm{SiO}_{2}\right)$ is produced by the reaction between sodium hydroxide and silica at a temperature of about $1000^{\circ} \mathrm{C}$ [11], which can give a certain strength to the mold. Therefore, the inorganic precursors should be homogeneously coated on the surfaces of starting particles and the conversion efficiency of the precursors coated on the substrate (starting particles) should be increased to improve the fracture strength.

Typical cross-sectional morphologies of particles in mold samples prepared by the dual dipping process used TEOS as the $\mathrm{SiO}_{2}$ precursor before the heat treatment are presented in Figure 2. The $\mathrm{NaOH}$ generated by the hydrolysis reaction of $\mathrm{NaOMe}$ has a particle layer with a polygonal shape, while the $\mathrm{SiO}_{2}$ by the sol-gel reaction of TEOS shows a layer with a continuous solid state on the surface of particle. The layer with a mixture of $\mathrm{SiO}_{2}$ and $\mathrm{NaOH}$ phases observed in the SEM image of the particle surface prepared through process I (Figure 2(a)) is due to the permeation of $\mathrm{SiO}_{2}$ precursor between the generated $\mathrm{NaOH}$ particles. However, in the case of Figure 2(b), two layers with $\mathrm{SiO}_{2}$ and $\mathrm{NaOH}$ 


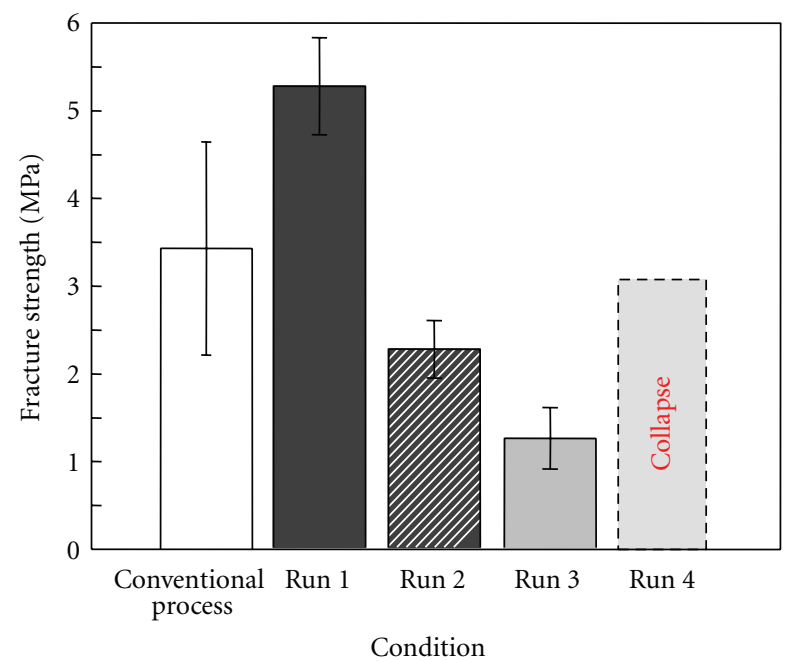

FIGURE 6: Fracture strength of mold samples after the heat treatment as functions of process and $\mathrm{SiO}_{2}$ precursor.

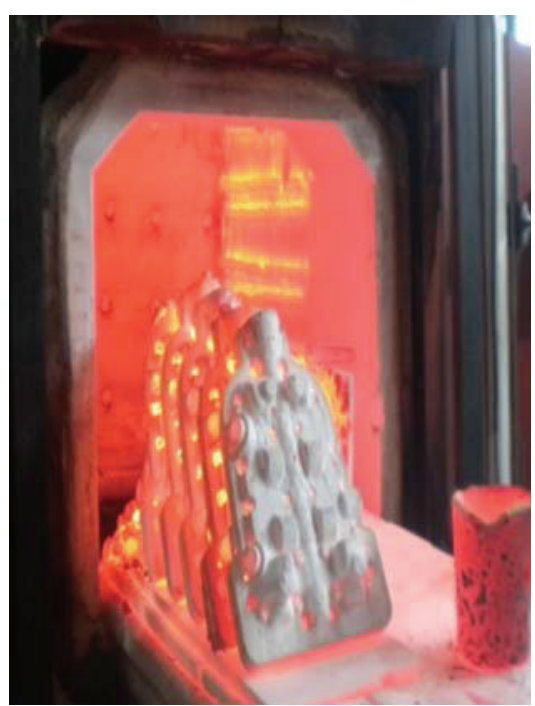

(a)

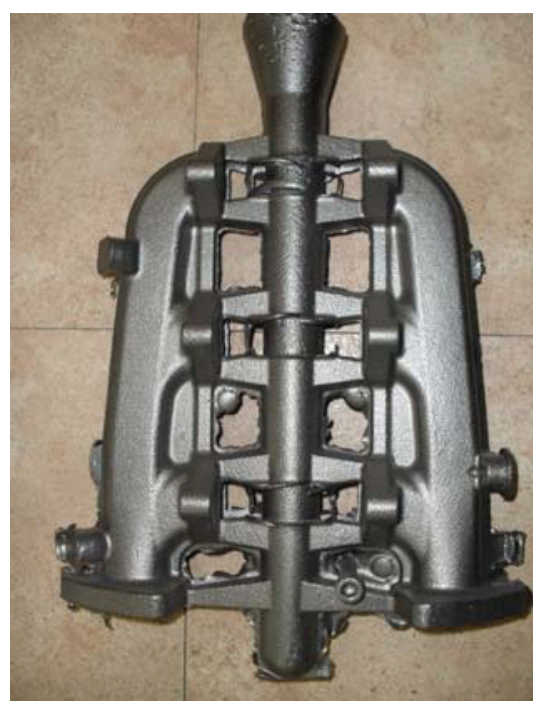

(b)

Figure 7: Photographs of real mold through process I with TEOS as the $\mathrm{SiO}_{2}$ precursor after the heat treatment at $950^{\circ} \mathrm{C}$ and fabricated product: (a) real mold and (b) casted product.

phases are independently formed on the surface of particle. This is because the continuous glass phase of $\mathrm{SiO}_{2}$ restricts the infiltration of $\mathrm{Na}_{2} \mathrm{O}$ precursor. Therefore, the layer formed by process I shows thinner thickness than that by process II. In process $\mathrm{I}$, the mixture phases of $\mathrm{SiO}_{2}$ and $\mathrm{NaOH}$ are converted into the glass phase of $\mathrm{Na}_{2} \mathrm{O} \cdot \mathrm{SiO}_{2}$ prior to the evaporation of $\mathrm{Na}$ ion decomposed from $\mathrm{NaOH}$ during the heat treatment, whereas in process II, $\mathrm{NaOH}$ existed at the outside of the layer is easily degraded and partially evaporated in the heat treatment. Therefore, the layer prepared by process I would be mainly composed of $\mathrm{Na}_{2} \mathrm{O} \cdot \mathrm{SiO}_{2}$, while in process II the layer would have the mixture composition of $\mathrm{Na}_{2} \mathrm{O} \cdot \mathrm{SiO}_{2}$ and $\mathrm{SiO}_{2}$. In addition, the inorganic precursors in process II have the lower conversion efficiency into the glass phase than those in process I owing to the easy evaporation of $\mathrm{Na}$ ion used to decrease the formation temperature of glass phase. It could be expected that the mold prepared through process I has a higher fracture strength than that prepared by process II.

The morphologies on the fracture surfaces of mold samples prepared through process $\mathrm{I}$ as a function of $\mathrm{SiO}_{2}$ precursor are shown in Figure 3. The surfaces of particles coated with the precursors are changed from rough to smooth during the heat treatment, caused by the generation of glass phase. In the case of PDMS used as the $\mathrm{SiO}_{2}$ precursor (Figure 3(b)), the glass phase is not fully developed at the interface and/or on the surface of particles. PDMS without the sol-gel reaction remains as a liquid phase and 
is easily evaporated during the heat treatment. However, TEOS is already converted into solid-phase silica before the heat treatment. Therefore, the fracture strength of samples prepared with PDMS could be significantly decreased, compared with that with TEOS. Typical SEM morphologies on the fracture surfaces of mold samples prepared by process II before and after the heat treatment are shown in Figure 4 as a function of $\mathrm{SiO}_{2}$ precursor. In process II, cracks are formed at the interface between particles and on the surface of particles before the heat treatment, denoted by the dotted arrow, whereas these cracks are not observed in process I (Figure 3). This is because the evaporation of alcohol used as the solvent of $\mathrm{NaOMe}$. In process $\mathrm{I}$, the evaporation of $\mathrm{Na}$ ion is disturbed by the layer of $\mathrm{SiO}_{2}$ precursor, whereas $\mathrm{Na}$ ion can be freely evaporated in process II, as pointed out in Figure 2. It is verified that the Na strongly affects the generation of glass phase, causing the higher strength in the mold prepared by process I than process II. In addition, in Figure 4(b-2), the glass phase is not presented at the interface and on the surface after the heat treatment, arising from the nonformation of glass phase owing to the easy evaporation of $\mathrm{Na}$ ion and PDMS existed as liquid phase during the heat treatment. Figure 5 is the SEM images of particle surfaces in the mold samples prepared by the conventional process and process I using TEOS as the $\mathrm{SiO}_{2}$ precursor. In Figure 5(b), the glass phase is homogeneous and uniform formed on the surface of particle. However, in Figure 5(a), the glass phase is locally and partially seen on the surface of particle.

The fracture strength of mold samples with the different processes and $\mathrm{SiO}_{2}$ precursors was measured at room temperature, and the results are shown in Figure 6. In general, the fracture strengths of mold samples prepared by process I (Runs 1 and 2) represent higher values than that by process II (Runs 3) due to the high reactivity between precursors, already mentioned at the results of SEM morphology. The mold treated by PDMS without the sol-gel reaction, especially in process II, absolutely collapsed owing to the deterioration in the formation of glass phase by the evaporation of $\mathrm{Na}$ ion and PDMS. In addition, the fracture strength through Run 1 is significantly enhanced, compared with the conventional binder process, caused by the enhancement of conversion efficiency and by the homogeneous formation of glass phase through the dual dipping process. It indicates that the mold for thin casting with reasonable mechanical properties could be fabricated by the new dual dipping process using inorganic binder precursors, inducing the reduction of product price. In addition, the dipping sequence in the dual dipping process is an essential point for increasing the efficiency and homogeneity of glassification and the fracture strength in the mold. Figure 7 shows a photograph of the real mold prepared through process I with TEOS as the $\mathrm{SiO}_{2}$ precursor after the heat treatment at $950^{\circ} \mathrm{C}$ for and the product fabricated by thin casting. The real mold prepared by the dual dipping process is perfectly produced and the casted product shows clean surface without defects such as dross, nonmetallic inclusions, and crack. Consequently, the new dual dipping process can be applied for preparing the mold for thin casting having high thermomechanical properties.

\section{Conclusions}

A new dual dipping process has been developed for the homogeneous formation of the glass phase on the surface of particles and at the interface between particles in the mold and to increase the reactivity between precursors, leading to the enhancement in the fracture strength of the mold. The glass phase is well and uniformly formed both at the interface and on the surface of particles in the mold prepared by process I, compared with that by process II. This is because the evaporation of $\mathrm{Na}$ ion generated by decomposition of $\mathrm{NaOH}$ is interrupted by the layers of $\mathrm{SiO}_{2}$ precursor in process I, while $\mathrm{Na}$ ion existed at the outside of particle surface is easily and partially evaporated in process II. In addition, when PDMS is used as the $\mathrm{SiO}_{2}$ precursor, the glass phase is partially or not absolutely formed in the mold, because PDMS existed as liquid phase without the sol-gel reaction after the dry process is deformed before the generation of glass phase during the heat treatment.

\section{Acknowledgments}

This work was supported by the National Research Foundation of Korea (NRF) Grant funded by the Korean government (MEST) (2011-0030797/2012-0009450), by the Korea Institute of Materials Science (KIMS) in 2012, and by the Changwon National University in 2011.

\section{References}

[1] Y. Meng and B. G. Thomas, "Modeling transient slag-layer phenomena in the shell/mold gap in continuous casting of steel," Metallurgical and Materials Transactions B, vol. 34, no. 5, pp. 707-725, 2003.

[2] M. Şimşir, L. C. Kumruoğlu, and A. Özer, "An investigation into stainless-steel/structural-alloy-steel bimetal produced by shell mould casting," Materials and Design, vol. 30, no. 2, pp. 264-270, 2009.

[3] M. Barsoum, Fundamentals of Ceramics, McGraw-Hill, Seoul, Republic of Korea, 1997.

[4] W. D. Callister, Materials Science and Engineering: An Introduction, John Wiley \& Sons, New York, NY, USA, 1997.

[5] S. Ege, Organic Chemistry, D. C. Heath and Company, Toronto, Canada, 1994.

[6] N. Sasaki, Foundry Management \& Technology February, 2009.

[7] B. M. Michael, Organic Chemistry, McGraw-Hill, New York, NY, USA, 1994.

[8] E. H. Kim, J. H. Lee, Y. G. Jung, C. S. Lee, and U. Paik, "A new in situ process in precision casting for mold fabrication," Journal of the European Ceramic Society, vol. 31, no. 9, pp. 1581-1588, 2011.

[9] E. H. Kim, W. R. Lee, Y. G. Jung, and C. S. Lee, "A new binder system for preparing high strength inorganic molds in precision casting," Materials Chemistry and Physics, vol. 126, no. 1-2, pp. 344-351, 2011.

[10] F. M. Herman, M. B. Norbert, G. O. Charles, and M. Georg, Encyclopedia of Polymer Science and Engineering, John Wiley \& Sons, New York, NY, USA, 1989.

[11] P. G. Shewmon, Diffusion in Solids, McGraw-Hill, New York, NY, USA, 1963. 

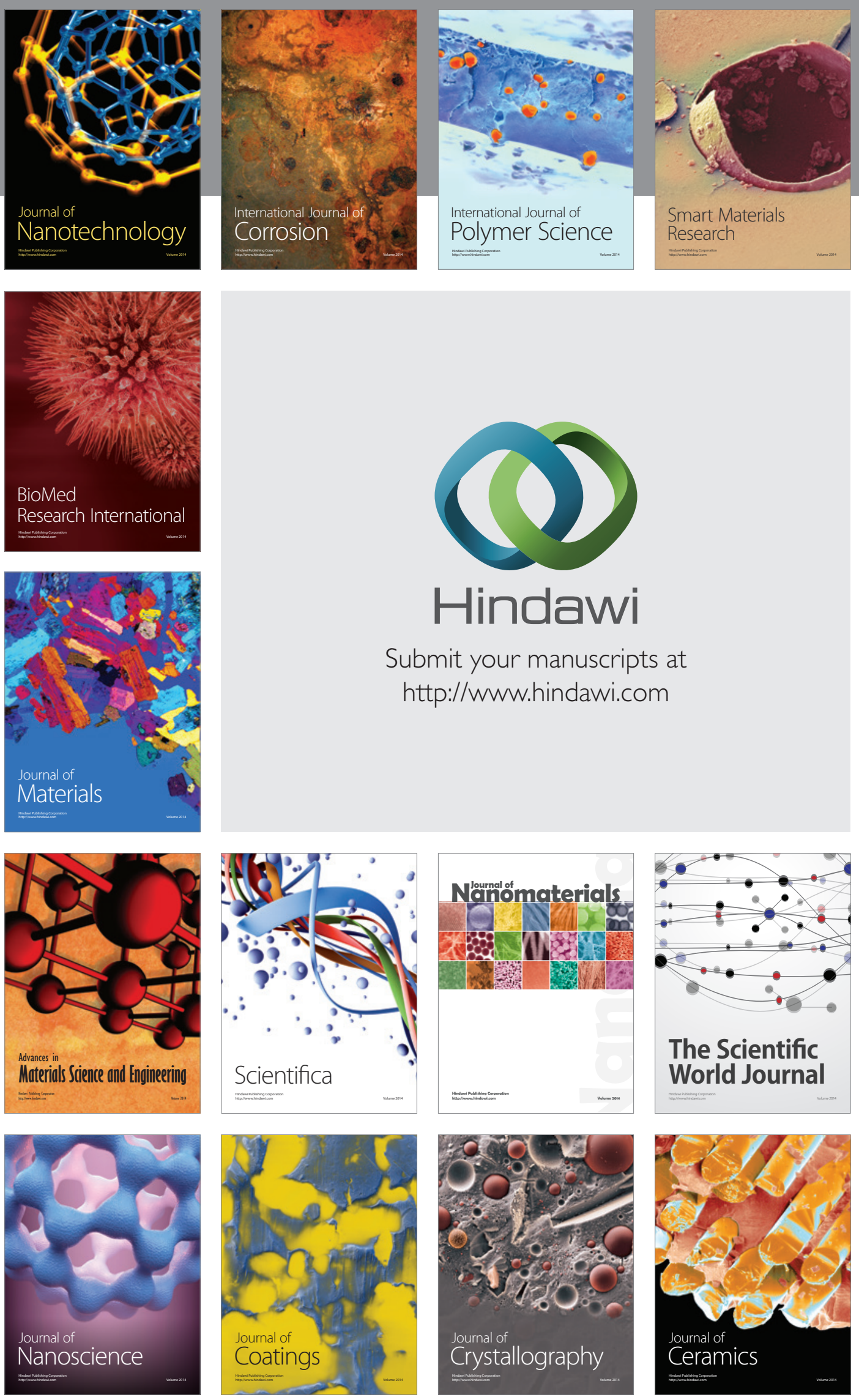

The Scientific World Journal

Submit your manuscripts at

http://www.hindawi.com

\section{World Journal}

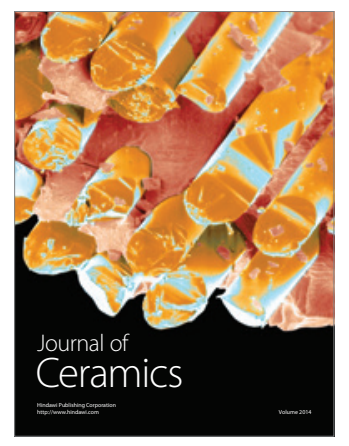

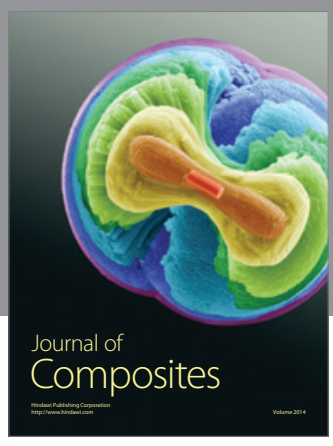
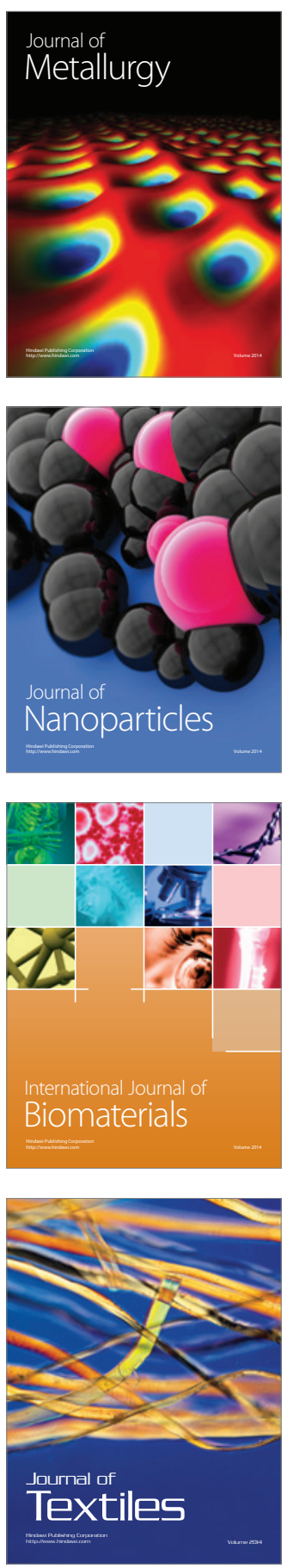